\title{
ACTIVITIES OF HEPATIC MICROSOMAL ELLCTRON TRANSPORT SYSTEM IN PROLONGED ETHANOL-TREATED RATS
}

\author{
Suchiro NAKANISHI, Eiko SHIOHARA, Miyoko TSUKADA \\ and Go KINOSHITA \\ Department of Pharmacology, Faculty of Medicine. Shinshu University, \\ Matsumoto, Japan
}

Accepted September 25, 1974

In previous studies, the authors reported that chronic ethanol feeding caused an increase in the amount of cytochrome P-450) and stimulated the p-hydroxylation of aniline, but had no effect on the $\mathrm{N}$-demethylation of aminopytine or the side-chain oxidation of hexobarbital by liver microsomes (1) (2). Holtzman et al. (3) pointed out that the $\mathrm{N}$ denethylation of ethylmorphine by liver microsomes was more closely related to NADPH cylochrome P-450 reductase activity than to the amount of cytochrome P-450. On the other hand, it has recently been revealed that cylochrome P-450 reductase activity decreases in the presence of aniline and increases in the presence of aminopyrine (4).

Thus in the present study, activities of main components of hepatic microsomal electron transport system in prolonged ethanol-treated rats were detemined in the presence of the drug substrate.

Male Wistar rats were used. Ethanol treatment and preparation of liver microsomes were the same as described previously (5). Rats of the ethanol group were given ethanol solution as drinking fluid ad hibitrm prior 10 sacrilice. All rats were fasted for $12 \mathrm{hr}$ prior to sacrifice. Cytochrome P-450 and $b_{5}$ contents were determined by the method of Holvman et al. (6) and of Barker and Smuckler (7) respectively. Assay for cylochrome P450 reductase activity was essentially the same as the method of Gigon et al. (4). Cytochrome c reductase and NADPH oxidase activity was assayed aceording to Phillips and Langdon (8) and Gillette el at. (9) respectively. Microsomal protein content was determined by the method of Lowry et al. (10).

Activities of cytochrome P-450 reductase, cytochrome c reduclase and NADPH oxidase of the ethanol group increased signilicantly in the absence of the drug substrate as compared with those of control rats. Activities of cytochrome P-450 reductase and cylochrome c reductase of the eltanol group in the presence of aminopyrine ( $3 \mathrm{mM}$ ) increased significantly, compared with those in the control group. With cylochrome P-450 reductase, however, there was no difference in the aminopyrine-enhanced rate of reduction of cytochrome P-450 between control and ethanol-treated rats. The magnitude of the stimulatory etiect of aminopyrine was the same in both groups (Table 1). In the presence of aniline $(2 \mathrm{mM})$ the rate of reduction of cytochrome $\mathrm{P}-450$ of the ethanol group was similar to that of the controls and the NADPH cytochrome c reductase activity of the 
TABI.F. 1. Cytochrome P-450 reductase activity of prolonged ethanol-treated rats in the absence and presence of aminopyrine.

Each experiment was carried out with microsomes from the same animal respectively.

\begin{tabular}{cccc}
\hline \multirow{2}{*}{ Groups } & \multicolumn{2}{c}{ Aminopyrine $(3 \mathrm{mM})$} & Difference \\
& Absence & Presence & \\
Control $(8)$ & $2.64 \pm 0.16$ & $4.20 \pm 0.44$ & $1.56 \pm 0.55$ \\
Ethanol-treated $(8)$ & $3.62 \div 0.50^{* *}$ & $5.24 \pm 0.55^{* *}$ & $1.47 \pm 0.31$ \\
\hline
\end{tabular}

Values are the mean values $t$ standard deviation. The number of animals used for each value is in parentheses. P-450 reductase activity : $J \mathrm{Abs}_{4: 0}$ sec/mg protein $\times 10^{-3}$ ** significantly different from control, $\mathrm{p}<0.01$

TABLE 2. Cytochrome P-450 reductase activity of prolonged ethanol-treated rats in the absence and presence of aniline.

Each experiment was carried out with microsomes from the same animal respectively.

\begin{tabular}{cccc}
\hline \multirow{2}{*}{ Groups } & \multicolumn{2}{c}{ Aniline $(2 \mathrm{mM})$} & Difference \\
& Absence & Presence & \\
Control (8) & $2.40 \pm 0.14$ & $1.71 \pm 0.13$ & $0.69 \pm 0.08$ \\
Ethanol-treated $(8)$ & $3.10 \div 0.22^{* *}$ & $1.96 \pm 0.24$ & $1.14 \div 0.14^{* *}$ \\
\hline
\end{tabular}

** significantly different from control, $\mathrm{p}<0.01$

ethanol group was significanly higher than that of the controls. The magnitude of the inhibitory effect of aniline in the ethanol group was higher than that in the control group (Table 2). There was no difference in the activity of NADPH oxidase bewween the control and ethanol groups in the presence of the drug substrate.

In the present study, the rate of reduction of cytochrome P-450 of the ethanol group was higher than that of the controls in the presence of aminopyrine although there was no difference in the aminopyrine-enhanced rate of reduction of cytochrome P-450 between the controls and ethanol-treated rats. There was no difference in the rate of reduction of cytochrome P-450 in the presence of aniline between the controls and ethanol group. The cytochrome $\mathrm{P}-450$ ) reductase activity of the ethanol group was more sensitive to aniline than that of the control rats. On the other hand, with drug hydroxylase activity p-hydroxylation of aniline increases significantly but $\mathrm{N}$-demethylation of aminopyrine in the ethanol group does nol increase (2). It is known that the rate of oxidation of aminopyrine by liver microsomes from 3-methylcholanthrene-treated rats is the same as the rate of reduction of cytochrome $\mathrm{P}-450$ in the presence of aminopyrine while the rate of oxidation of aniline is about $10 \%$ that of aminopyrine (11). These tindings suggest that the rate-limiting step of aminopyrine $\mathrm{N}$-demethylation may be the rate of reduction of cytochrome P-450 while the reduction of the hemoprotein is not limiting in p-hydroxylation reaction of aniline.

At present, the relationship hetween microsonal hydroxylase activity and cytochrome 
P-450 reductase activity in the ethanol-treated rats is difficult to interprete. The results obtained in the present study suggest that part of the cytochrome P-450 fraction which increased by chronic ethanol ingestion may be different qualitatively from that of the control rats.

\title{
REFERENCFS
}

1) Nakanishi, S., Masamura, E., Tsujada, M., Miyazawa, T. and Matsumura, R.: Med. $J$. Shirh.shu Univ. 15, 91 (1970); 2) Nakanishi, S., Kinoshrta, G., Sillollara, E. and Tsukada, M.: Japan. J. Pharmacol. 22, 809 (1972); 3) Holtzmal, J.L., Gram, T.E., Gigon, P.L. and Gillette, J.R.: Fedin. Proc. 27, 838 (1968); 4) Grgon, P.L., Gram, T.E. and Gillette, J.R.: Mol. Pharmacol. 5, 109 (1969); 5) Nakanisht, S., Masamura, E., Tsukada, M. and Matsumura, R, Japan. J. Pharmacol. 21, 303 (1971); 6) Holtzman, J.L., Gram, T.E., Gigon, P.L. and Gillette, J.R.: Biochem. J. 110, 407 (1968); 7) Barker, E.A. ANd SMuckler, E.A.: Mol. Pharmacol. 8, 318 (1972); 8) Phillies, A.H. AND LANGdon, R.G.: J. biol. Chem. 237, 2652 (1962); 9) Gilletre, J.R., Bromie, B.B. and La DU, B.N.: J. Pharmacol. exp. Ther. 119, 532 (1957); 10) Lowry, O.H., Rosebrough, N.J., Farr, A.L. And Randall, R.J.: J. biol. Chem. 193, 265 (1951): (1) Scilenkman, J.B.: Mol. Pharmacol. 8, 178 (1972)

\section{EFFECT OF 4-PENTENOIC ACID ON LIPIDS IN PLASMA AND LIVER OF RATS}

\author{
Tadashi FUJITA and Masahide YASUDA \\ Deparment of Hygienic Chemistry, Osaka College of Pharmacy, \\ Matsuhara, Osaka, Janan
}

Accepted October 4, 1974

It has been reported that 4-pentenoic acid (4-PA) inhibited fatty acid oxidation in in vitro systems, but causes little inhibition of oxidative phosphorylation in mitochondria $(1,2,3)$. Kleinman et al. (4) have suggested that in vivo perfusion of dog kidneys with 4-PA produces a natriuresis, kaliuresis, and bicarbonate diuresis independent of changes in renal hemodynamics and which appear to be due to inhibition of the metabolic energy sources for active transport. To consider the biological action of 4-PA, we have examined the effects of 4-PA on free fatty acids (FFA) and triglycerides (TG) in plasma and liver of rats, and also attempted to determine its effect on the peroxidation of polyunsaturated fatty acid.

Wistar strain male rats, weighing 150 to $250 \mathrm{~g}$, were used as cest subjects. 4-PA in saline solution or saline alone for control was injected i.p.. 4-PA was given once a day at a dose of $50 \mathrm{mg} / \mathrm{kg}$ for 3 days. Blood samples were taken from all rats after which the animals were exsanguinated. The liver was removed $24 \mathrm{hr}$ after the final treatment. Plasma and liver homogenate (prepared in ice-cold $0.25 \mathrm{M}$ sucrose, 1:9, w/v) were used as samples to be assayed for FFA and TG. Mitochondrial fraction was prepared by the method of Hogeboom (5). Protein was determined by the method of Lowry et al. (6). 